\title{
Potent triazine-based dehydrocondensing reagents substituted by an amido group
}

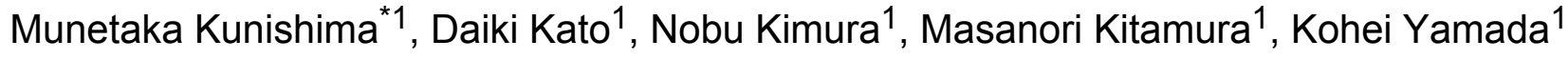 \\ and Kazuhito Hioki ${ }^{2}$
}

\author{
Full Research Paper \\ Address: \\ ${ }^{1}$ Faculty of Pharmaceutical Sciences, Institute of Medical, \\ Pharmaceutical, and Health Sciences, Kanazawa University, \\ Kakuma-machi, Kanazawa 920-1192, Japan and ${ }^{2}$ Faculty of \\ Pharmaceutical Sciences, Kobe Gakuin University, 1-1-3 Minatojima \\ Chuo-ku, Kobe 655-8586, Japan \\ Email: \\ Munetaka Kunishima* - kunisima@p.kanazawa-u.ac.jp \\ * Corresponding author \\ Keywords: \\ amide-forming reactions; amido substituents; dehydrocondensing \\ reactions; Fischer-type esterification; triazines
}

\author{
Beilstein J. Org. Chem. 2016, 12, 1897-1903. \\ doi:10.3762/bjoc. 12.179 \\ Received: 31 May 2016 \\ Accepted: 05 August 2016 \\ Published: 24 August 2016 \\ Associate Editor: R. Sarpong \\ (c) 2016 Kunishima et al.; licensee Beilstein-Institut. \\ License and terms: see end of document.
}

\begin{abstract}
This study describes the synthesis of triazine-based dehydrocondensing reagents substituted by amido substituents and demonstrates their efficiency for dehydrocondensing reactions in $\mathrm{MeOH}$ and THF. $N$-Phenylbenzamido-substituted chlorotriazine is readily converted to a stable, non-hygroscopic triazinylammonium-based dehydrocondensing reagent that is superior to 4-(4,6dimethoxy-1,3,5-triazin-2-yl)-4-methylmorpholinium chloride (DMT-MM) in terms of its reactivity in dehydrocondensing reactions.
\end{abstract}

\section{Introduction}

We previously reported that dehydrocondensing reactions between carboxylic acids $\mathbf{1}$ and amines $\mathbf{2}$ to give amides $\mathbf{3}$ efficiently proceed in water or alcohols in the presence of the dehydrocondensing reagent, 4-(4,6-dimethoxy-1,3,5-triazin-2-yl)-4methylmorpholinium chloride (DMT-MM) (Scheme 1a,b) [1-5]. The mechanism of the reaction shown in Scheme $1 \mathrm{~b}$ involves the acyloxytriazine intermediate 4 , which has appropriate reactivity and sufficient stability to hydrolysis or alcoholysis. This feature enables the use of DMT-MM for dehydrocondensing reactions in water or alcohols to give amides without the recovery of hydrolyzed carboxylic acids and the formation of corresponding esters. DMT-MM is quantitatively synthesized from 2-chloro-4,6-dimethoxy-1,3,5-triazine (CDMT) and $\mathrm{N}$-methylmorpholine (NMM). Related triazinylammonium salts (DMT-Am) can be prepared from other tertiary amines $\mathbf{5}$ instead of NMM (Scheme 1c) [6].

Since the direct reaction of carboxylates with CDMT is very slow, the formation of DMT-Am is essential for the conversion of carboxylates into 4 [7]. Therefore, we developed catalytic 
(a)

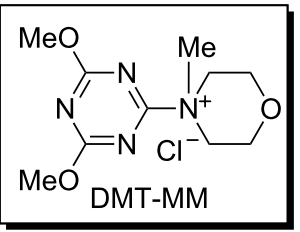

(b)

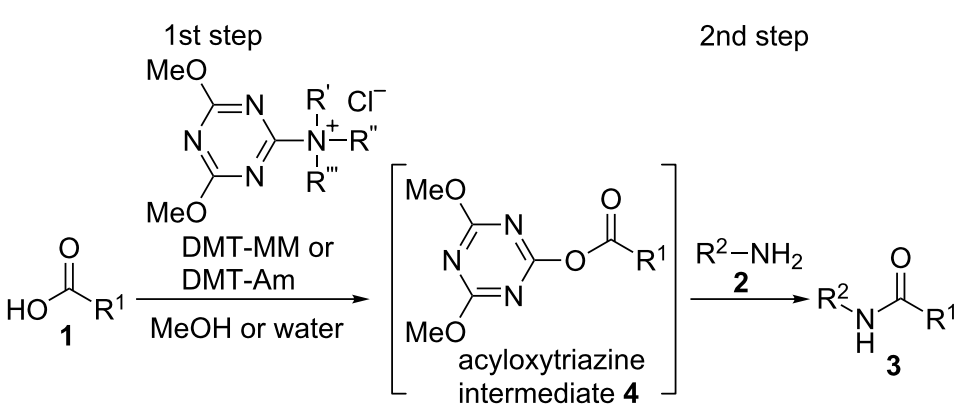

(c)

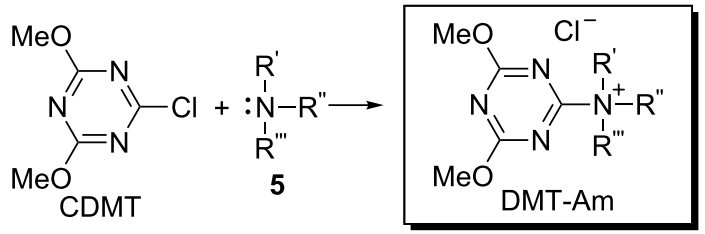

(d)

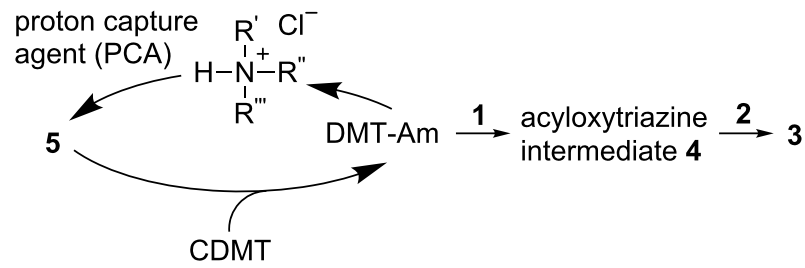

Scheme 1: Dehydrocondensing reactions using DMT-MM or DMT-Am, and a catalytic amide-forming reaction.

amide-forming reactions in water using triazinylammonium salts (DMT-Am) generated in situ from CDMT and a catalytic amount of tertiary amines 5 (Scheme 1d). Most notably, by introducing various functional groups into $\mathbf{5}$, it was possible to develop a cyclodextrin-based artificial acyltransferase [7], a crown-ether-based cyclotransferase [8], membrane fusion of small unilamellar vesicles to form giant unilamellar vesicles [9], modular methods for the affinity labeling of targeting proteins [10-12], and reaction acceleration on micelle interfaces $[13,14]$ Thus, various types of molecular recognitions of carboxylic acids were affected by fuctionalized DMT-Am. However, once the reaction with 1 takes place, the functionalized tertiary amines 5 liberated, no longer affect the following reaction (Scheme 1d). As a consequence, the resulting acyloxyatriazine intermediate 4, which is the same intermediate in Scheme 1b, basically shows the same reactivity for aminolysis and alcoholysis regardless of which tertiary amine 5 was used (Scheme 1b,d). Therefore, it is reasonable to modify the activity of the 1,3,5-triazine ring that is involved in both steps shown in Scheme $1 \mathrm{~b}$ by introducing another substituent in place of the methoxy groups.

To date, several triazine derivatives possessing phenoxy [15,16], 2,2,2-trifluoroethoxy [17], or $N$-ethylamino groups [18] in place of the methoxy groups have been prepared, and the reactivity of these compounds in amide-forming reactions has been examined. The reactivity of triazine was found to slightly increase following the introduction of electron-withdrawing phenoxy or 2,2,2-trifluoroethoxy groups and decrease upon the inclusion of an electron-donating $N$-ethylamino group. This result may indicate that the tuning of the $\pi$-electron density within the triazine ring is important in either enhancing or suppressing its reactivity. To find a novel triazine-based dehydrocondensing reagent, we are focusing on the effect of substituents on the triazine ring. In this paper, we report the synthesis and reactivity of triazine-based dehydrocondensing reagents that have an amido group in place of the methoxy groups of CDMT or DMT-MM.

\section{Results and Discussion}

We decided to use an amido group as a substituent on the triazine ring instead of a methoxy group based on Hammett substituent constants, which indicate that an acetamido group is a more electron-withdrawing group $\left(\sigma_{\mathrm{m}}=0.31\right.$ for $-\mathrm{NMeCOMe}$, 0.21 for $-\mathrm{NHCOMe}$, and 0.12 for $-\mathrm{OMe}$ [19]). In addition, we expected that the appropriate substitution pattern of amido groups $\left(\mathrm{R}^{3}\right.$ and $\mathrm{R}^{4}$ in Figure 1) would enable the precise control of the reactivity of triazines in dehydrocondensing reactions. We therefore synthesized various secondary or tertiary amidetype chlorotriazines (I-VI) by the substitution of only one methoxy group of CDMT because it is straightforward to evaluate the effect of a single amido substituent. For the design and synthesis of $\mathbf{I}-\mathbf{V I}$, acetamido and benzamido groups were selected as the amido substituents $\left(\mathrm{R}^{3}=\mathrm{Me}\right.$ or $\left.\mathrm{Ph}\right)$, and the methyl, phenyl, or hydrogen substituent was placed at $R^{4}$.

Tertiary amide-type compounds III-VI were prepared in one step from the well-known commercially available 2,4-dichloro6-methoxy-1,3,5-triazine (6) [20] (Scheme 2). In contrast, attempts to prepare the secondary amide-type I and II using the 


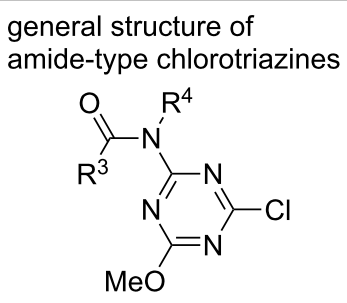

secondary amide-type chlorotriazines<smiles>COc1nc(Cl)nc(NC(C)=O)n1</smiles><smiles>COc1nc(Cl)nc(NC(=O)c2ccccc2)n1</smiles>

tertiary amide-type chlorotriazines<smiles>COc1nc(Cl)nc(N(C)C(C)=O)n1</smiles>

III<smiles>COc1nc(Cl)nc(N(C)C(=O)c2ccccc2)n1</smiles><smiles>COc1nc(Cl)nc(N(C(C)=O)c2ccccc2)n1</smiles>

IV

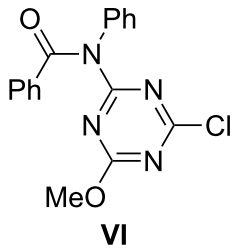

Figure 1: Structures of amido-substituted chlorotriazines. same method resulted in low yields mainly because of the substitution of the methoxy group of $\mathbf{6}$ by amido anions (Supporting Information File 1). Thus, these compounds were successfully synthesized using an alternative method starting from cyanuric chloride via an intermediate 7 (Scheme 2).

Single-crystal X-ray structure analysis, two-dimensional NMR spectroscopy, or derivatization of I-VI was performed to unambiguously determine their structures, i.e., whether the $N$ - or $O$-substituted derivative was prepared from the amido anion (Supporting Information File 1).

To evaluate the reactivity of these chlorotriazines in amideforming reactions, one-pot reactions were performed (Table 1a), i.e., the chlorotriazines were added to a mixture of carboxylic acid 1a, amine 2a, and NMM in $\mathrm{MeOH}$ or THF at room temperature. The amide-forming reaction in the absence of NMM did not proceed, meaning that triazinylmorpholinium salts are the actual reactive species (Supporting Information File 1). To permit an accurate comparison between the chlorotriazines, all amide-forming reactions presented in Table 1 were conducted for $3 \mathrm{~h}$.

Compared with CDMT, low yields of the amide 3a were obtained using the secondary amide-type I and II, possibly because of the low solubilities of I and II in the reaction solvents owing to the acidic proton of the secondary amide. When using III-VI, which were soluble in reaction solvents, the yields of 3a in both $\mathrm{MeOH}$ and THF, particularly the high yield of 3a obtained using benzamido-substituted VI, were comparable with those obtained using CDMT.

For III-VI $\left(\mathrm{R}^{4}=\mathrm{Me}\right.$ or $\left.\mathrm{Ph}\right)$<smiles>COc1nc(Cl)nc(Cl)n1</smiles>

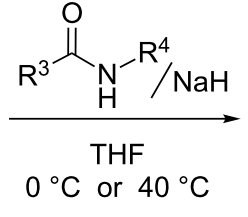<smiles>[R]C(=O)N([R])c1nc(Cl)nc(OC)n1</smiles>

III, $R^{3}=M e, R^{4}=M e: 35 \%$

IV, $\mathrm{R}^{3}=\mathrm{Me}, \mathrm{R}^{4}=\mathrm{Ph}: 63 \%$

V, $R^{3}=P h, R^{4}=M e: 84 \%$

VI, $\mathrm{R}^{3}=\mathrm{Ph}, \mathrm{R}^{4}=\mathrm{Ph}: 82 \%$

For I-II $\left(R^{4}=H\right)$

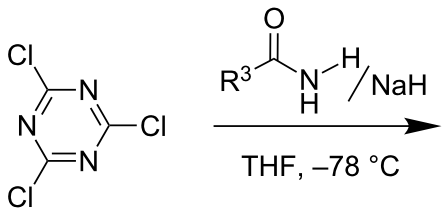<smiles>[R]C(=O)Nc1nc(Cl)nc(Cl)n1</smiles><smiles>CO[Mg]O[Mg]</smiles>

7a: $R^{3}=$ Me: $36 \%$

$7 b: R^{3}=P h: 65 \%$<smiles>[R]C(=O)Nc1nc(Cl)nc(OC)n1</smiles>

I: $\mathrm{R}^{3}=\mathrm{Me}, 67 \%$

II: $\mathrm{R}^{3}=\mathrm{Ph}, 78 \%$ 
Table 1: Amide-forming reactions using chlorotriazines (I-VI) or triazinylammonium salts (VII-X)

(a) in situ amidation (one-pot reaction)

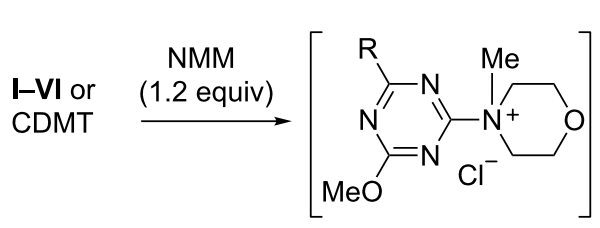

(b) preparation of condensing reagents

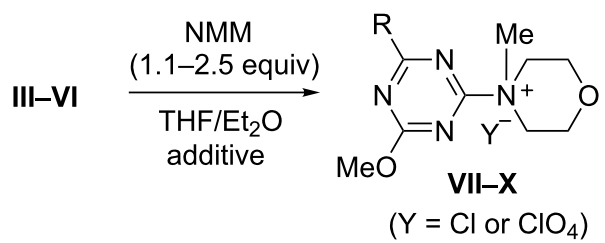

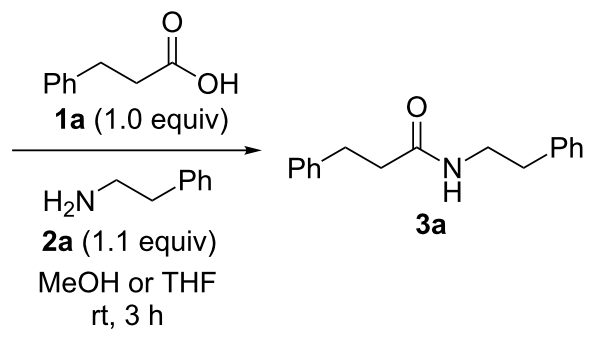

(c) amidation with condensing reagents

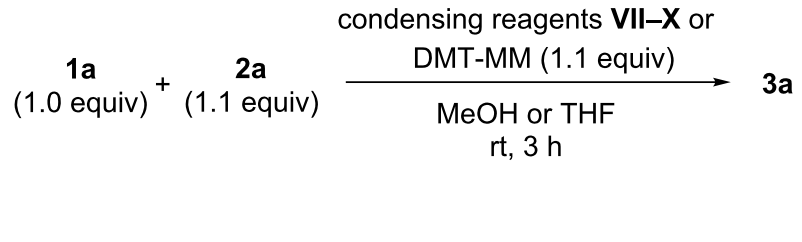

\begin{tabular}{|c|c|c|c|c|c|c|c|}
\hline \multirow[b]{2}{*}{ chlorotriazine } & \multicolumn{2}{|c|}{$\begin{array}{c}\text { (a) in situ amidation } \\
\text { yield (\%) }\end{array}$} & \multicolumn{3}{|c|}{ (b) preparation of condensing reagents (VII-X) } & \multicolumn{2}{|c|}{$\begin{array}{c}\text { (c) amidation using } \\
\text { VII-X } \\
\text { yield (\%) }\end{array}$} \\
\hline & in $\mathrm{MeOH}$ & in THF & & additive & yield $(\%)$ & in $\mathrm{MeOH}$ & in THF \\
\hline CDMT & 88 & 81 & DMT-MM & - & 100 & 98 & 84 \\
\hline I & 70 & 55 & $-^{a}$ & $-^{a}$ & $-^{a}$ & $-^{a}$ & $-^{a}$ \\
\hline II & 86 & 80 & $-^{a}$ & $-{ }^{\mathrm{a}}$ & $-a$ & $-a$ & $-{ }^{a}$ \\
\hline III & 95 & 60 & VII $\left(Y=\mathrm{ClO}_{4}\right)^{\mathrm{b}}$ & $\mathrm{LiClO}_{4}$ (1.1 equiv) & 98 & 75 & 50 \\
\hline IV & 90 & 73 & VIII $\left(Y=\mathrm{ClO}_{4}\right)^{\mathrm{b}}$ & $\mathrm{LiClO}_{4}(1.1$ equiv) & 91 & 88 & 84 \\
\hline $\mathbf{v}$ & 91 & 72 & $\mathbf{I X}(\mathrm{Y}=\mathrm{CI})^{\mathrm{b}}$ & - & 90 & 75 & 81 \\
\hline VI & 93 & 79 & $\mathbf{X}(\mathrm{Y}=\mathrm{Cl})^{\mathrm{b}}$ & - & 80 & 95 & 89 \\
\hline
\end{tabular}

aThe reaction was not conducted. ${ }^{\mathrm{b}}$ The counter anions were shown in parentheses.

From these results, dehydrocondensing reagents (VII-X, Table 1) were prepared from III-VI and NMM (Table 1b). Although benzamido-substituted $\mathbf{I X}$ and $\mathbf{X}$ could be readily synthesized, acetamido-substituted triazines were hygroscopic, and therefore, VII and VIII were prepared as stable, non-hygroscopic reagents by counterion exchange in the presence of $\mathrm{LiClO}_{4}[6]$.

Amide-forming reactions using the dehydrocondensing reagents VII-X were then examined (Table 1c). While $\mathbf{X}$ afforded a good yield (95\% in $\mathrm{MeOH}$ and $89 \%$ in THF) of the amide 3a in both solvents, slightly low yields $(75-88 \%$ in $\mathrm{MeOH}$ and $50-84 \%$ in THF) for VII and VIII were obtained, possibly because of the low solubilities of these reagents in the investigated solvents (perchlorate salts have generally low solubilities).

We then analyzed the NMR spectra of crude mixtures obtained from the reactions using III (THF solvent, Table 1a) or VII
(THF solvent, Table 1c) and identified $N$-acetyl-2-phenylethylamine in $29 \%$ and $25 \%$ yields, respectively. This byproduct was formed by the aminolysis of the $\mathrm{N}$-methylacetamido group on the triazine ring by $\mathbf{2 a}$. A similar phenomenon was observed for IV or VIII in THF. Notably, such a byproduct was not obtained in the case of $\mathbf{V}, \mathbf{I X}, \mathbf{V I}$, and $\mathbf{X}$. In $\mathrm{MeOH}$, no such byproduct resulting from aminolysis was observed in all the cases.

We employed $\mathbf{X}$ to further study the synthesis of various amides with a particular focus on the stability and non-hygroscopic property of the reagent (Table 2). In most cases, $\mathbf{X}$ exhibited similar reactivity in $\mathrm{MeOH}$ compared with DMT-MM, and the amides 3 were obtained with negligible formation of the corresponding methyl ester 8 (Table 2, entries 1, 5, 7, and 9). In the case of the sterically hindered secondary amine $\mathbf{2 c}$, methyl ester $\mathbf{8}$ was obtained as a byproduct in $31 \%$ and $24 \%$ yields for $\mathbf{X}$ and DMT-MM (Table 2, entry 3), respectively. In contrast, the yields obtained in THF using $\mathbf{X}$ were superior to those obtained 
Table 2: Substrate scope of carboxylic acids 1 and amines 2.

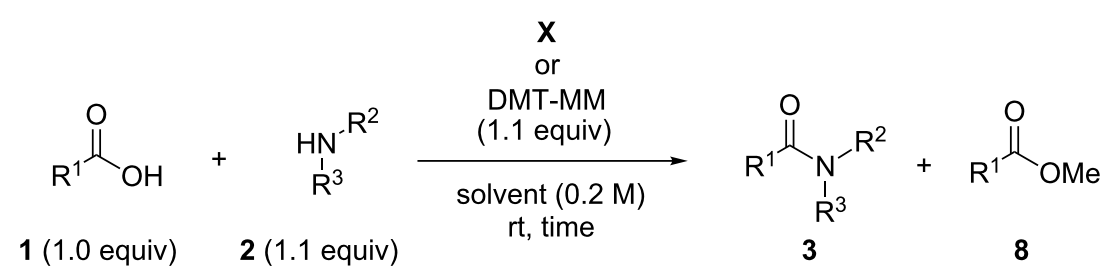

\begin{tabular}{|c|c|c|c|c|c|c|c|c|c|c|}
\hline \multirow[b]{3}{*}{ entry } & \multirow[b]{3}{*}{ carboxylic acid } & \multirow[b]{3}{*}{ amine } & \multirow[b]{3}{*}{ amide } & \multirow[b]{3}{*}{ solvent } & \multicolumn{3}{|c|}{$\mathbf{x}$} & \multicolumn{3}{|c|}{ DMT-MM } \\
\hline & & & & & \multirow[b]{2}{*}{ time $(\mathrm{h})$} & \multicolumn{2}{|c|}{ yield $(\%)^{a}$} & \multirow[b]{2}{*}{ time $(\mathrm{h})$} & \multicolumn{2}{|c|}{ yield $(\%)^{a}$} \\
\hline & & & & & & 3 & 8 & & 3 & 8 \\
\hline 1 & \multirow{2}{*}{$\mathrm{Ph} \overbrace{1 \mathrm{a}}^{\mathrm{CO}_{2} \mathrm{H}}$} & \multirow{2}{*}{$\begin{array}{c}\mathrm{H}_{2} \mathrm{~N}-\mathrm{Ph} \\
\mathbf{2 b}\end{array}$} & \multirow{2}{*}{$3 b$} & $\mathrm{MeOH}$ & 6 & 80 & (1) & 24 & 73 & $(0)$ \\
\hline 2 & & & & THF & 6 & 75 & - & 24 & 16 & - \\
\hline 3 & \multirow{2}{*}{$1 \mathrm{a}$} & \multirow{2}{*}{$\begin{array}{l}\mathrm{HNEt}_{2} \\
\text { 2c }\end{array}$} & \multirow{2}{*}{$3 c$} & $\mathrm{MeOH}$ & 6 & 65 & (31) & 9 & 56 & 24 \\
\hline 4 & & & & THF & 4 & 85 & - & 4 & $68^{b}$ & - \\
\hline 5 & \multirow{2}{*}{$\begin{array}{c}t-\mathrm{BuCO}_{2} \mathrm{H} \\
\mathbf{1 b}\end{array}$} & \multirow{2}{*}{$\mathrm{H}_{2} \mathrm{~N} \widehat{2 a}$} & \multirow[b]{2}{*}{$3 d$} & $\mathrm{MeOH}$ & 6 & (87) & (3) & 6 & (89) & $(0)$ \\
\hline 6 & & & & THF & 3 & $(90)$ & - & 3 & (86) & - \\
\hline 7 & \multirow{2}{*}{$\begin{array}{c}\mathrm{PhCO}_{2} \mathrm{H} \\
\text { 1c }\end{array}$} & \multirow[b]{2}{*}{$2 a$} & \multirow{2}{*}{$3 e$} & $\mathrm{MeOH}$ & 4 & 97 & (8) & 3 & 90 & (1) \\
\hline 8 & & & & THF & 4 & 95 & - & 4 & $81^{b}$ & - \\
\hline 9 & \multirow{2}{*}{$p-\mathrm{O}_{2} \mathrm{~N}-\mathrm{C}_{6} \mathrm{H}_{4} \mathrm{CO}_{2} \mathrm{H}$} & \multirow{2}{*}{$2 a$} & \multirow{2}{*}{$3 f$} & $\mathrm{MeOH}$ & 4 & 91 & $(2)$ & 3 & 86 & (4) \\
\hline 10 & & & & THF & 4 & 96 & - & 3 & $82^{b}$ & - \\
\hline
\end{tabular}

alsolated yields. ${ }^{1} \mathrm{H}$ NMR yields are given in parentheses. ${ }^{\mathrm{b}}$ From reference [2].

using DMT-MM (Table 2, entries 4, 6, 8, and 10), especially for the poorly nucleophilic aniline $\mathbf{2 b}$ (Table 2 , entry 2 ).

To elucidate the reactivities of $\mathbf{X}$ and DMT-MM, time courses of amide-forming reactions using sterically hindered pivalic acid (1b) and 2-phenylethylamine (2a) in $\mathrm{MeOH}$ and THF were investigated by ${ }^{1} \mathrm{H}$ NMR spectroscopy (Figure 2a,b, respectively). The steric hindrance of $\mathbf{1 b}$ was suitable to investigate the reaction rates for $\mathbf{X}$ and DMT-MM. Although the final yields of the amide were almost the same for both triazines, the rate of the reaction with $\mathbf{X}$ was faster than that with DMT-MM, particularly in THF.

Similarly, time courses of the basic Fischer-type esterification of 3-phenylpropanoic acid (1a) in neat $\mathrm{MeOH}$ were studied (Figure 3). Although $\mathbf{X}$ was shown to exist as a dihydrate by elemental analysis and single-crystal X-ray structure analysis, the yield of methyl 3-phenylpropanoate was quantitative. The rate of esterification with $\mathbf{X}$ was faster than that with DMTMM.

\section{Conclusion}

We prepared triazine-based dehydrocondensing reagents bearing amido substituents and demonstrated their efficiency for their use in dehydrocondensing reactions in both $\mathrm{MeOH}$ and THF. The tertiary amide-type chlorotriazines III-VI gave better yields of the product 3a compared with the secondary amidetype chlorotriazines I and II, possibly because of the reduced solubilities of I and II in the reaction solvents. VI is readily converted to a triazinylammonium-based dehydrocondensing reagent as a chloride salt $(\mathbf{X})$, which is stable and non-hygroscopic. The dehydrocondensing reagent $\mathbf{X}$ is superior to DMT$\mathrm{MM}$ in terms of reactivity in dehydrocondensing reactions. Although DMT-MM is the appropriate reagent for dehydrocondensing reactions in large-scale synthesis, $\mathbf{X}$ have advantage for dehydrocondensing reactions in aprotic solvents such as THF, especially when low nucleophilic starting materials such as aniline were used. This study contributes to the development of novel functionalized triazine-based dehydrocondensing reagents that are effective for aminolysis or alcoholysis shown in the second step of Scheme $1 \mathrm{~b}$. 


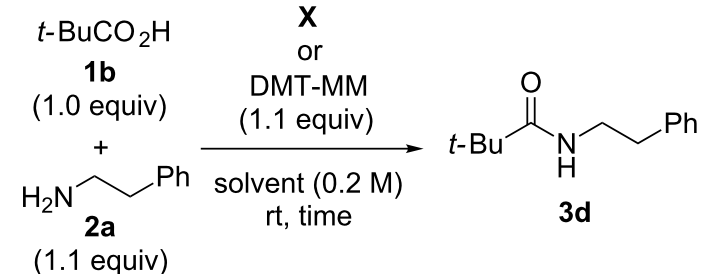

(a) in $\mathrm{MeOH}$

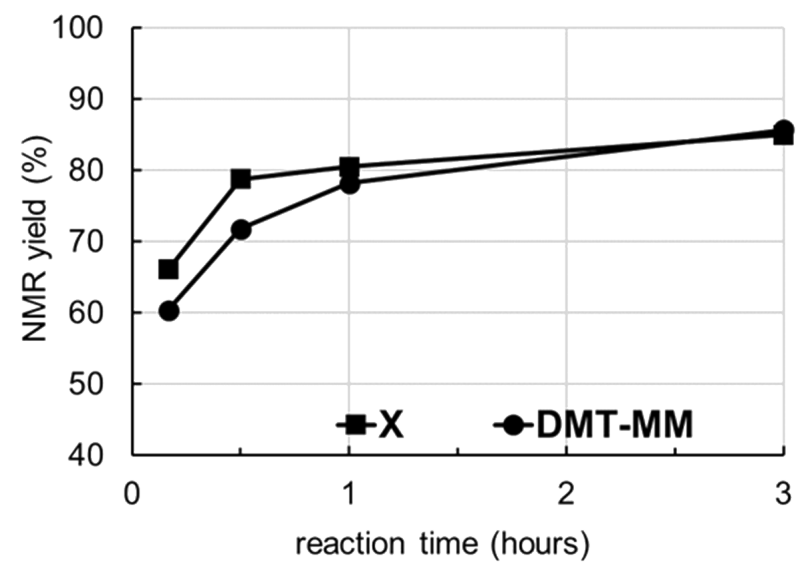

(b) in THF

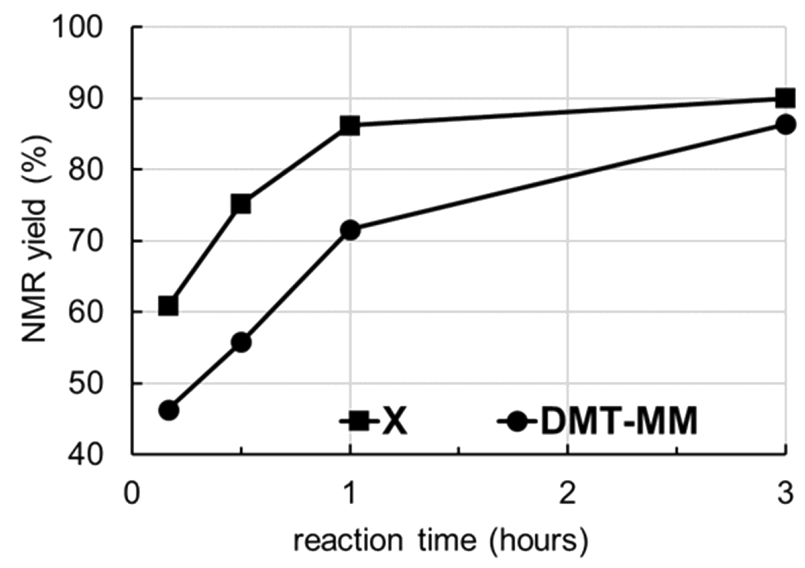

Figure 2: Time courses of the amide-forming reactions.
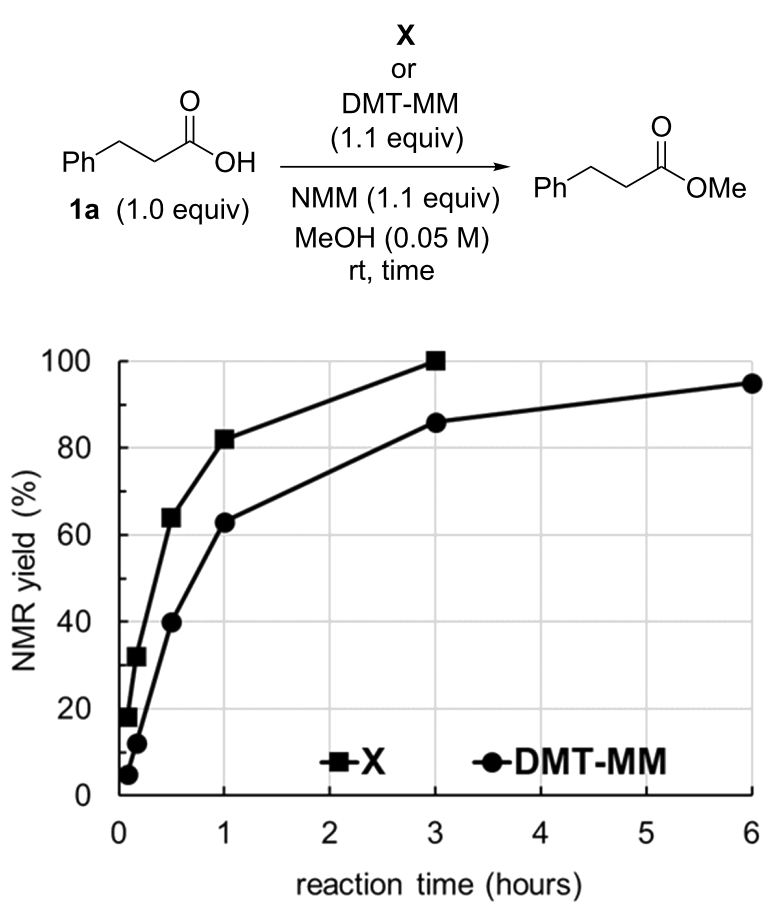

Figure 3: Time courses of the basic Fischer-type esterification.

\section{Supporting Information}

General information, synthesis of triazines $\mathbf{I}-\mathbf{X}$ and structure determination, spectral data of amides $\mathbf{3}$, attempted synthesis of $\mathbf{I}$ from $\mathbf{6}$, amide-forming reaction with VI in the absence of NMM, and copies of ${ }^{1} \mathrm{H}$ and ${ }^{13} \mathrm{C}$ NMR spectra of unknown compounds are given.

\section{Supporting Information File 1}

Experimental and characterization data.

[http://www.beilstein-journals.org/bjoc/content/ supplementary/1860-5397-12-179-S1.pdf]

\section{Acknowledgements}

This work was supported by JSPS KAKENHI Grant (No. 26293003).

\section{References}

1. Kunishima, M.; Kawachi, C.; Iwasaki, F.; Terao, K.; Tani, S. Tetrahedron Lett. 1999, 40, 5327-5330. doi:10.1016/S0040-4039(99)00968-5

2. Kunishima, M.; Kawachi, C.; Monta, J.; Terao, K.; Iwasaki, F.; Tani, S. Tetrahedron 1999, 55, 13159-13170. doi:10.1016/S0040-4020(99)00809-1 
3. Kunishima, M.; Kawachi, C.; Hioki, K.; Terao, K.; Tani, S. Tetrahedron 2001, 57, 1551-1558. doi:10.1016/S0040-4020(00)01137-6

4. Kitamura, M.; Kunishima, M.

4-(4,6-Dimethoxy-1,3,5-triazin-2-yl)-4-methylmorpholinium chloride. In e-EROS (Encyclopedia of Reagents for Organic Synthesis) [Online]; Crich, D.; Charette, A. B.; Fuchs, P. L., Eds.; John Wiley \& Sons, Ltd: West Sussex, 2013. doi:10.1002/047084289X.rn01530

5. Dunetz, J. R.; Magano, J.; Weisenburger, G. A.

Org. Process Res. Dev. 2016, 20, 140-177. doi:10.1021/op500305s See for a recent review for other coupling reagents; and references are therein.

6. Kunishima, M.; Ujigawa, T.; Nagaoka, Y.; Kawachi, C.; Hioki, K.; Shiro, M. Chem. - Eur. J. 2012, 18, 15856-15867. doi:10.1002/chem.201202236

7. Kunishima, M.; Yoshimura, K.; Morigaki, H.; Kawamata, R.; Terao, K.; Tani, S. J. Am. Chem. Soc. 2001, 123, 10760-10761. doi:10.1021/ja011660m

8. Kunishima, M.; Hioki, K.; Moriya, T.; Morita, J.; Ikuta, T.; Tani, S. Angew. Chem. 2006, 118, 1274-1277. doi:10.1002/ange.200504027 Angew. Chem., Int. Ed. 2006, 45, 1252-1255. doi:10.1002/anie.200504027

9. Kunishima, M.; Tokaji, M.; Matsuoka, K.; Nishida, J.; Kanamori, M.; Hioki, K.; Tani, S. J. Am. Chem. Soc. 2006, 128, 14452-14453. doi:10.1021/ja0652969

10. Kunishima, M.; Nakanishi, S.; Nishida, J.; Tanaka, H.; Morisaki, D.; Hioki, K.; Nomoto, H. Chem. Commun. 2009, 5597-5599. doi:10.1039/b912908a

11. Nakanishi, S.; Tanaka, H.; Hioki, K.; Yamada, K.; Kunishima, M. Bioorg. Med. Chem. Lett. 2010, 20, 7050-7053. doi:10.1016/j.bmcl.2010.09.109

12. Kitamura, M.; Kawasaki, F.; Ogawa, K.; Nakanishi, S.; Tanaka, H.; Yamada, K.; Kunishima, M. J. Org. Chem. 2014, 79, 3709-3714. doi:10.1021/jo500376m

13. Kunishima, M.; Imada, H.; Kikuchi, K.; Hioki, K.; Nishida, J.; Tani, S. Angew. Chem. 2005, 117, 7420-7423. doi:10.1002/ange.200502594 Angew. Chem., Int. Ed. 2005, 44, 7254-7257. doi:10.1002/anie.200502594

14. Kunishima, M.; Kikuchi, K.; Kawai, Y.; Hioki, K. Angew. Chem. 2012, 124, 2122-2125. doi:10.1002/ange.201107706 Angew. Chem., Int. Ed. 2012, 51, 2080-2083. doi:10.1002/anie.201107706

15. Kamiński, Z. J. Tetrahedron Lett. 1985, 26, 2901-2904. doi:10.1016/S0040-4039(00)98867-1

16. Jastrząbek, K.; Kolesińska, B.; Sabatino, G.; Rizzolo, F.; Papini, A. M.; Kamiński, Z. J. Int. J. Pept. Res. Ther. 2007, 13, 229-236. doi:10.1007/s10989-006-9071-y

17. Jastrzabek, K. G.; Subiros-Funosas, R.; Albericio, F.; Kolesinska, B.; Kamiński, Z. J. J. Org. Chem. 2011, 76, 4506-4513. doi:10.1021/jo2002038

18. Kunishima, M.; Yamamoto, K.; Hioki, K.; Kondo, T.; Hasegawa, M.; Tani, S. Tetrahedron 2007, 63, 2604-2612. doi:10.1016/j.tet.2007.01.034

19. Hansch, C.; Leo, A.; Taft, R. W. Chem. Rev. 1991, 91, 165-195. doi:10.1021/cr00002a004

20. Tanaka, T.; Noguchi, M.; Watanabe, K.; Misawa, T.; Ishihara, M.; Kobayashi, A.; Shoda, S.-i. Org. Biomol. Chem. 2010, 8, 5126-5132. doi:10.1039/c0ob00190b

\section{License and Terms}

This is an Open Access article under the terms of the Creative Commons Attribution License (http://creativecommons.org/licenses/by/4.0), which permits unrestricted use, distribution, and reproduction in any medium, provided the original work is properly cited.

The license is subject to the Beilstein Journal of Organic Chemistry terms and conditions:

(http://www.beilstein-journals.org/bjoc)

The definitive version of this article is the electronic one which can be found at:

doi:10.3762/bjoc. 12.179 